\title{
A horizontal mobile measuring system for atmospheric quantities
}

\author{
J. Hübner ${ }^{1}$, J. Olesch ${ }^{1}$, H. Falke ${ }^{2}$, F. X. Meixner ${ }^{3}$, and T. Foken ${ }^{1,4}$ \\ ${ }^{1}$ University of Bayreuth, Department of Micrometeorology, 95440 Bayreuth, Germany \\ ${ }^{2}$ Gesellschaft für Akustik und Fahrzeugmeßwesen mbH, 08058 Zwickau, Germany \\ ${ }^{3}$ Max Planck Institute for Chemistry, Biogeochemistry Department, 55020 Mainz, Germany \\ ${ }^{4}$ Member of Bayreuth Center of Ecology and Environmental Research (BayCEER), University of Bayreuth, \\ 95440 Bayreuth, Germany
}

Correspondence to: J. Hübner (joerg.huebner@uni-bayreuth.de)

Received: 25 September 2013 - Published in Atmos. Meas. Tech. Discuss.: 7 May 2014

Revised: 30 July 2014 - Accepted: 30 July 2014 - Published: 16 September 2014

\begin{abstract}
A fully automatic horizontal mobile measuring system (HMMS) for atmospheric quantities has been developed. The HMMS is based on the drive mechanism of a garden railway system and can be installed at any location and along any measuring track. In addition to meteorological quantities (temperature, humidity and short-/longwave down/upwelling radiation), HMMS also measures trace gas concentrations (carbon dioxide and ozone). While sufficient spatial resolution is a problem even for measurements on distributed towers, this could be easily achieved with the HMMS, which has been specifically developed to obtain higher information density about horizontal gradients in a heterogeneous forest ecosystem. There, horizontal gradients of meteorological quantities and trace gases could be immense, particularly at the transition from a dense forest to an open clearing, with large impact on meteorological parameters and exchange processes. Consequently, HMMS was firstly applied during the EGER IOP3 project (ExchanGE processes in mountainous Regions - Intense Observation Period 3) in the Fichtelgebirge Mountains (SE Germany) during summer 2011. At a constant $1 \mathrm{~m}$ above ground, the measuring track of the HMMS consisted of a straight line perpendicular to the forest edge, starting in the dense spruce forest and leading $75 \mathrm{~m}$ into an open clearing. Tags with bar codes, mounted every metre on the wooden substructure, allowed (a) keeping the speed of the HMMS constant (approx. $0.5 \mathrm{~m} \mathrm{~s}^{-1}$ ) and (b) operation of the HMMS in a continuous back and forth running mode. During EGER IOP3, HMMS was operational for almost $250 \mathrm{~h}$. Results show that - due to considerably long response times (between 4 and $20 \mathrm{~s}$ )
\end{abstract}

of commercial temperature, humidity and the radiation sensors - true spatial variations of the meteorological quantities could not be adequately captured (mainly at the forest edge). Corresponding dynamical (spatial) errors of the measurement values were corrected on the basis of well-defined individual response times of the sensors and application of a linear correction algorithm. Due to the very short response times $(\leq 1 \mathrm{~s})$ of the applied commercial $\mathrm{CO}_{2}$ and $\mathrm{O}_{3}$ analysers, dynamical errors for the trace gas data were negligible and no corrections were done.

\section{Introduction}

The heterogeneity of terrestrial surfaces requires high spatially resolved measurements of atmospheric quantities to quantify their heterogeneous structure close to the surface. Forest ecosystems, which cover a large portion of the Earth's surface, are particularly affected by increasing heterogeneity due to wind throws, pests and human activities, such as deforestation. High spatial resolution can be achieved by sampling at various locations (Oncley et al., 2009). This can be realised either by a large number of locally fixed sensors or by (fast moving) mobile measuring systems.

Application of mobile measuring systems started in the middle of the last century. They are used when the spatial representation of the investigation site is required to be as exact as possible, and the number of available, locally fixed sensors is insufficient. In former studies, mobile measuring systems mostly carried radiometers above and 
under forest canopies to measure the areal distribution of upwelling and/or downwelling radiation (e.g. Leonard and Eschner, 1968; Mukammal, 1971; Brown, 1973; Baldocchi et al., 1984a, b; Péch, 1986; Lee and Black, 1993; Chen et al., 1997; Privette et al., 1997; Blanken et al., 2001). Comparable measurements above grasslands were taken by Rodskjer and Kornher $(1967,1971)$. To study wind velocity and tower-induced errors of its measurements, Dabberdt (1968) built a mobile system which carried an anemometer. Örlander and Langvall (1993) and Langvall and Löfvenius (2002) describe their "Asa-Shuttle", a mobile system, which measures, in addition to radiation, the air temperature along a horizontal transect of decreasing shelterwood density of Norway spruce. The system of Singh et al. (2008) is able to move in two dimensions, the vertical and horizontal. They used their system for the study of river and lake aquatic systems. The mobile system of Gamon et al. (2006) carries a dual-detector spectrometer to measure ecosystem spectral reflectance. The TRAM (Transect Measurement) system of Oncley et al. (2009) runs in a loop, measuring wind velocity (ultrasonic anemometer), the $\mathrm{CO}_{2}$ concentration, air temperature and humidity. They were able to create a measurement track through a forest ecosystem and over a creek (AmeriFlux site at Niwot Ridge) through the use of steel cables and masts, which allowed mobile measurements over a long horizontal distance and also changing of the vertical measurement height. Besides the mobile platforms mentioned above, there are investigations with mobile measurements in aircrafts, balloons, lifts and other mobile platforms (e.g. Lenschow, 1972; Kaimal et al., 1976; Ogawa and Ohara, 1982; Balsley et al., 1992, 1998; Friehe and Khelif, 1992; Muschinski et al., 2001; Mayer et al., 2009).

Focusing on energy and matter exchange at a forest edge, the EGER IOP3 project (ExchanGE processes in mountainous Regions - Intense Observation Period 3) was conducted in a disturbed forest ecosystem where heterogeneities will substantially impact exchange processes between atmosphere, vegetation and soil. Forest edges in particular may have greater effects on exchange processes in a heterogeneous forest ecosystem. Driving forces at the forest edge are spatial differences of up- and downwelling radiation, temperature, moisture, and the resulting wind regime (Murcia, 1995; Matlack and Litvaitis, 1999; Davies-Colley et al., 2000; Klaassen et al., 2002). Forest edges and prevailing gradients were targeted in a variety of micrometeorological studies. Chen et al. $(1993,1995)$ focused on a Douglasfir forest (Pacific Northwest, USA). Dawson and Sneddon (1969), McDonald and David (1992) as well as DaviesColley et al. (2000) investigated the edge of rain forest next to a clearing in New Zealand. Newmark (2001) studied four forest edges in the West and East Usambara Mountains (Tanzania). Even flux measurements at forest edges and numerical studies have been performed (see Dupont et al., 2011, for a detailed overview). First results of the EGER IOP3 project are presented in Eder et al. (2013), showing an increased number of coherent structures at the forest edge, which might be an indication of a quasi-stationary secondary circulation. A detailed description of secondary circulations can be found in Glickman (2000), and for site-specific conditions see Eder et al. (2013).

The horizontal mobile measuring system (HMMS) presented in this paper is a fully automatic system moving on rails. The chosen measuring transect for EGER IOP3 was a straight line, installed perpendicular to the forest edge. However, a greater variation in the measuring height along the track is limited because of the wooden substructure and also because of the limited climbing ability of the HMMS (maximum climbing angle: $<10 \%$ ). The HMMS was equipped with long-wave and short-wave radiation sensors (individual sensors for up- and downwelling radiation), a sensor for air temperature and relative humidity, and analysers for $\mathrm{CO}_{2}$ and $\mathrm{O}_{3}$ concentrations. Foken et al. (2012) had shown that trace gas concentrations are good tracers for coherent structures and coupling regimes and we expected to find sources or sinks in the horizontal structures, which might be an indication for the influence of vertical structures such as coherent structures, or secondary circulations. The selection of appropriate sensors was a major challenge, because of (a) the limited power of the drive mechanism, leading to payload restrictions for sensors and electronics, (b) the space on the carrier platform restricting the size of sensors, analysers, and electronics, and (c) the requirement for short response times in order to capture the true spatial variations of meteorological quantities and trace gas concentrations (with the highest variations occurring mainly at the forest edge) within an acceptable time. Besides the technical description of the HMMS (Sect. 2.1), we present the results of laboratory tests for the individual sensor response times, some short time series of the measurements and the application of a correction algorithm (Sect. 2.2) to correct the measurements for the response time induced dynamical error.

\section{Materials and methods}

\subsection{Description of HMMS}

The technical description of the HMMS comprises details of the drive mechanism and the design of the carrier, the software and the sensor system. The front and lateral view of the HMMS are shown in Fig. 1, with the corresponding descriptions listed in Table 1. Table 2 contains the sensors' details. For more technical details of the HMMS, including technical drawings, pictures and the detailed wiring plan, see Hübner et al. (2011).

\subsubsection{Drive mechanism and carrier design}

The drive mechanism of the HMMS is from a commercial garden railway system (Lehmann-Groß-Bahn, LGB, since 2007 part of Gebr. Märklin \& Cie. GmbH, 

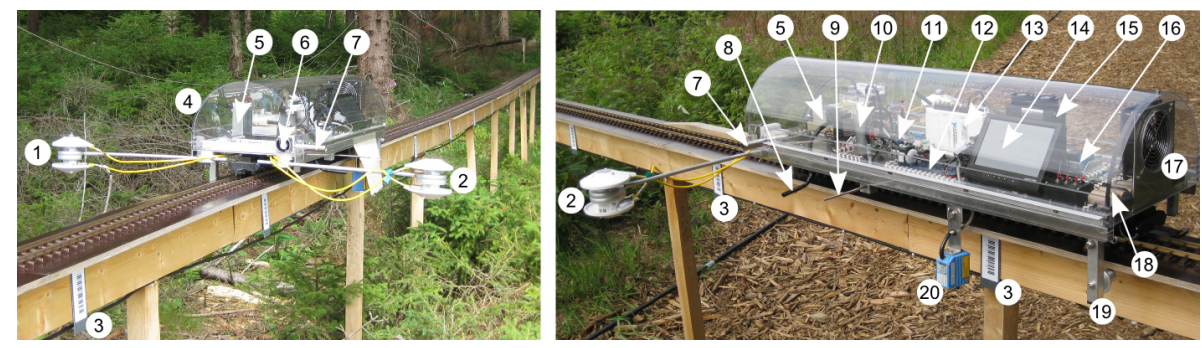

Figure 1. Front and lateral view of the HMMS. Specifications of the numbers are in Table 1.

Table 1. Specification of numbers from Fig. 1.

\begin{tabular}{llll}
\hline No. & Description & No. & Description \\
\hline 1 & Short-wave radiation sensors on a 0.4 m long boom & 11 & Pump for $\mathrm{CO}_{2}$ analyser \\
2 & Long-wave radiation sensors on a $0.4 \mathrm{~m}$ long boom & 12 & Edinburgh Instruments Ltd. Gascard ${ }^{\circledR} \mathrm{NG} \mathrm{CO}_{2}$ analyser \\
3 & Code 39 bar code & 13 & National Instruments DAQ device \\
4 & Makrolon ${ }^{\circledR}$ cover to protect the HMMS from rain and dirt & 14 & 7 ” TFT monitor \\
5 & Enviscope $\mathrm{O}_{3}$ analyser & 15 & Micro PC \\
6 & Fan for ventilation of the HMP 155 & 16 & LGB Analog throttle with potentiometer \\
7 & Inlet for $\mathrm{HMP}^{\prime}$ 155, double shielded & 17 & Fan for cooling the entire system \\
8 & Inlet for $\mathrm{O}_{3}$ analyser, made of PTFE & 18 & On-board storage battery \\
9 & Inlet for $\mathrm{CO}_{2}$ analyser, made of aluminium & 19 & Lateral holder to protect the HMMS against falls \\
10 & Pump for $\mathrm{O}_{3}$ analyser & 20 & Sick CLV412-1010 bar code scanner \\
\hline
\end{tabular}

Göppingen, Germany). The drive mechanism (two DC engines and wheels) were removed from a replica Diesel hydraulic locomotive and mounted under an aluminium plate $(300 \mathrm{~mm} \times 1000 \mathrm{~mm})$ incorporating a downward-facing $\mathrm{U}$ profile to increase mechanical stability. This plate serves as the carrier platform of the (a) sensors, (b) data acquisition, and (c) control system for speed and position. The HMMS moves on original LGB rails with a track gauge of $45 \mathrm{~mm}$. The rails are made of brass: due to its high electrical conductivity, electrical power for the entire HMMS system was supplied through the rails (infeed: 24 V DC, 5 A). This infeed covers the total requirement of the HMMS, which is approx. $3 \mathrm{~A}$ for all devices, and the rest is used for the drive mechanism, differing depending on the speed and/or the inclination. The power was fed in continuously every $25 \mathrm{~m}$ starting in the middle of the HMMS track (forest edge) and going in both directions (feed points were at positions: 25, 50, 75, $100,125 \mathrm{~m}$ ) to avoid power loss over long distances. Springmounted pick-up shoes (sliding contacts) on both sides of the engines tapped the power from the rails.

Speed and the driving direction of the HMMS are controlled by an analogue throttle (provided by LGB). Its potentiometer is controlled via the HMMS software and a data acquisition (DAQ) device with an analogue output (for a more detailed description of the DAQ device see Sect. 2.1.2). The output of the analogue throttle can be set ranging from 0 V DC (motor standstill) to 24 V DC (full throttle), with the polarity determining direction ( + : forwards, - : backwards).
The power supply of the engines with maximum $24 \mathrm{~V}$ DC is the first electrical circuit on the HMMS, but the sensors and Micro PC of the HMMS need a $12 \mathrm{~V}$ DC supply with constant polarity. This is provided by a DC/DC-converter in the second electrical circuit of the HMMS, which has a programmable and stabilised output. Occasional breakdowns of electrical power are buffered by an on-board storage battery (12 V DC, $0.8 \mathrm{Ah}$ ).

For determination of position and speed, as well as for changing the driving direction, the HMMS was equipped with a commercial raster bar code scanner (CLV412-1010, SICK Vertriebs GmbH, Düsseldorf, Germany). The applied "Code 39" bar code contains information of the distance from the starting point. Besides determination of the position and speed, it is possible to programme distinct speed profiles along the measuring track. The position of each bar code can be used as a turning point for reversing the driving direction of the HMMS.

A transparent cover, made of Makrolon ${ }^{\circledR}$, was attached to the carrier platform to protect HMMS electronics and sensors against dirt and moisture (i.e. drizzle and short showers, but not prolonged wet conditions). Four lateral holders at each corner of the carrier platform (No. 19 in Fig. 1) prevent the HMMS from falling (measuring height during EGER IOP3: $1 \mathrm{~m})$. 
Table 2. Sensors mounted on the HMMS are two pyranometers (down- and upwelling, $K_{\downarrow}, K_{\uparrow}$ ), two pyrgeometers (down- and upwelling, $\left.L_{\downarrow}, L_{\uparrow}\right)$, a temperature $(T)$ and relative humidity sensor $(\mathrm{RH})$, a $\mathrm{CO}_{2}$ analyser $\left(\mathrm{CO}_{2}\right)$ and an $\mathrm{O}_{3}$ analyser $\left(\mathrm{O}_{3}\right)$. The accuracies are taken from the manufacturers' information.

\begin{tabular}{llll}
\hline Parameter & Sensor & Accuracy & Remark \\
\hline$K_{\downarrow}$ & Kipp \& Zonen CMP3 & $<15 \mathrm{~W} \mathrm{~m}^{-2}$ & Amplifier used (Factor: 50-fold) \\
$K_{\uparrow}$ & Kipp \& Zonen CMP3 & $<15 \mathrm{~W} \mathrm{~m}^{-2}$ & Amplifier used (Factor: 100-fold) \\
$L_{\downarrow}$ & Kipp \& Zonen CGR3 & $<15 \mathrm{~W} \mathrm{~m}^{-2}$ & Amplifier used (Factor: 500-fold); optional PT-100 temperature sensor \\
$L_{\uparrow}$ & Kipp \& Zonen CGR3 & $<15 \mathrm{~W} \mathrm{~m}^{-2}$ & Amplifier used (Factor: 500-fold); optional PT-100 temperature sensor \\
$T$ & Vaisala HMP155 & $\pm 0.1 \mathrm{~K}$ & Radiation shield and ventilated with $4 \mathrm{~m} \mathrm{~s}^{-1}$ \\
$\mathrm{RH}$ & Vaisala HMP155 & $\pm 1 \%$ & Radiation shield and ventilated with $4 \mathrm{~m} \mathrm{~s}^{-1}$ \\
$\mathrm{CO}_{2}$ & Edinburgh Instruments Gascard ${ }^{\circledR}$ & $\pm 40 \mathrm{ppm}$ & Vacuum pump DC24/16F (Flow rate: $1.2 \mathrm{~L} \mathrm{~min}^{-1}$ ) \\
$\mathrm{O}_{3}$ & NG CO 1000 ppm & & \\
\hline
\end{tabular}

* Accuracy at a measuring frequency of $1 \mathrm{~Hz}$ and a mixing ratio of $50 \mathrm{ppbv}\left(1 \mathrm{ppbv}=\right.$ mixing ratio of $\left.10^{-9}\right)$.

\subsubsection{Software and data acquisition system}

The HMMS software (Gesellschaft für Akustik und Fahrzeugmeßwesen mbH (GAF), Zwickau, Germany) was installed on a Micro PC (Quanmax QBOX-1010). This is a very small, light-weight and low-power BOX PC (power consumption approx. 1 A) with a sufficient number of ports to connect all parts of the HMMS. All measured data were stored on the internal hard disk drive (HDD) of the QBOX-1010.

Through a 16 bit data acquisition (DAQ) device (USB-6211, National Instruments, Austin, USA) the HMMS software manages the control of speed, the determination of position, the driving direction and the data acquisition of the HMMS. The DAQ device, a very compact box with 16 analogue input and two analogue output channels (with an additional four digital inputs/outputs), handles the two pyranometers, the two pyrgeometers, two extra PT-100 temperature sensors for the pyrgeometers, and the air temperature and humidity sensor. The $\mathrm{CO}_{2}$ and $\mathrm{O}_{3}$ analysers and the bar code scanner are connected via serial ports directly to the QBOX-1010. For a detailed overview of all applied sensors see Sect. 2.1.3.

The sensors' sampling rate can be set in the range of 1 to $5 \mathrm{~Hz}$, with a 200 times higher internal oversampling rate to improve resolution and reduce potential (although highly unlikely) aliasing effects, caused for example by noises of the power frequency (Bentley, 2005). Oversample mode is a common practice also used in data loggers. Because of the movement of the HMMS, we used only the first $10 \%$ of the internal sampling rate for linear averaging, in order to allocate the measured values to an exact position, without having blurring effects. Depending on the chosen sampling rate, data files are updated on the HDD of the QBOX-1010.

\subsubsection{Sensor system}

Due to the demands placed on the sensor system, mentioned in the Introduction, the final selection of sensors and analysers resulted in a compromise between their weight/size and acceptable response times. The latter may be described by the time constant, which is a sensor/analyser specific quantity. Generally, the smaller the time constant, the smaller are the dynamical errors and consequently the spatially smoothing effects of the measurements. An overview of the HMMS sensors and analysers is given in Table 2, and more detailed information, particularly of their individual time constants $\tau_{63}$ - which have been determined in our own laboratory tests (see Sect. 3.1) - are given in Table 3.

For air temperature and relative humidity measurements, the HMMS was equipped with a HMP155 temperature and humidity (HUMICAP ${ }^{\circledR}$ 180R) probe (Vaisala Oyj, Vantaa, Finland). Both sensors of the HMP155 probe had the highest time constants of all HMMS sensors. A common practice to reduce these time constants is to place the sensors in an aspirated radiation shield tube. To achieve that, the two sensors were detached from the original sensor housing and the sintered PTFE filter, and were then mounted in a double thermal radiation shield tube after Assmann (Assmann, 1887, 1888) and Frankenberger (Frankenberger, 1951). Aspiration has been facilitated by a small PC fan maintaining a constant air flow of approx. $4 \mathrm{~m} \mathrm{~s}^{-1}$ within the tube. According to the manufacturer's information, the time constant of both sensors of the original HMP155 probe is $<20 \mathrm{~s}$. While our modifications reduced the time constant of the temperature sensor to approx. $12 \mathrm{~s}$, there was no change of the relative humidity sensor's time constant. Both time constants have been determined in our laboratory tests (see Sect. 3.1). Since the sintered PTFE filter was removed from the HMP155 probe, we changed the relative humidity sensor approx. every 70 operating hours during EGER IOP3 to minimise potential problems of humidity measurements due to the accumulation of 
Table 3. Results of calculation of the sensor response time with the given signal differences $\Delta X_{\mathrm{i}}$ in the laboratory test and its consequences on the location of the measured data. The spatial relocation is shown for a positive or negative signal difference, with the possible effect of hysteresis. For the sensors used see Table 2.

\begin{tabular}{lllllll}
\hline Parameter & Signal difference $\Delta X_{\mathrm{i}}$ & $\tau_{63}$ & Delay time & Hysteresis & \multicolumn{2}{c}{ Spatial relocation for $0.5 \mathrm{~m} \mathrm{~s}^{-1}$} \\
\cline { 6 - 7 } & & & & & $+\Delta X_{\mathrm{i}}$ & $-\Delta X_{\mathrm{i}}$ \\
\hline$K_{\downarrow}, K_{\uparrow}$ & $350 \mathrm{~W} \mathrm{~m}^{-2}$ & $4 \mathrm{~s}^{\mathrm{a}}$ & - & no & $12 \mathrm{~m}$ & $12 \mathrm{~m}$ \\
$L_{\downarrow}, L_{\uparrow}$ & $150 \mathrm{~W} \mathrm{~m}^{-2}$ & $4 \mathrm{~s}^{\mathrm{a}}$ & - & no & $14 \mathrm{~m}$ & $14 \mathrm{~m}$ \\
$T$ & $5 \mathrm{~K}$ & $12 \mathrm{~s}^{\mathrm{b}}$ & - & yes & $21 \mathrm{~m}$ & $19 \mathrm{~m}$ \\
$\mathrm{RH}$ & $15 \%$ & $20 \mathrm{~s}^{\mathrm{a}}$ & - & yes & $23 \mathrm{~m}$ & $20 \mathrm{~m}$ \\
$\mathrm{CO}_{2}$ & $480 \mathrm{ppm}$ & $<1 \mathrm{~s}^{\mathrm{a}}$ & $0.2 \mathrm{~s}^{\mathrm{d}}$ & no & $3 \mathrm{~m}$ & $3 \mathrm{~m}$ \\
$\mathrm{O}_{3}$ & - & $<0.1 \mathrm{~s}^{\mathrm{c}}$ & $0.5 \mathrm{~s}^{\mathrm{d}}$ & no & $0.5 \mathrm{~m}$ & $0.5 \mathrm{~m}$ \\
\hline
\end{tabular}

${ }^{a}$ In agreement with the data given by the manufacturer. ${ }^{b} 8 \mathrm{~s}$ shorter than data given by the manufacturer due to sensor modification.

${ }^{\mathrm{c}}$ Developed for high-frequency measurements $(50 \mathrm{~Hz}), \tau_{63}$ is negligible (no laboratory test conducted). ${ }^{\mathrm{d}}$ Delay time caused by the inlet length.

dust on the sensor. In comparison with measurements by locally fixed (aspirated) sensors close to the HMMS track, we did not observe an increasing deviation in the humidity measurements between the HMMS and the locally fixed measurements, even after more than 250 operating hours.

A total of four radiation sensors were mounted on the HMMS: two pyranometers (CMP3, short-wave radiation, $0.3-2.8 \mu \mathrm{m})$ and two pyrgeometers (CGR3, long-wave radiation, $4.5-42 \mu \mathrm{m})$ to measure down- and upwelling radiation (Kipp \& Zonen, Delft, The Netherlands). The sensor housing temperature of the pyrgeometer was measured with a Pt-100 temperature sensor (replacing the original thermistor sensor). Whereas the sensors are installed with no modifications, the time constants of the sensors are consistent with the manufacturer's information (verified in own laboratory tests, Sect. 3.1). Since the output voltage of the thermopiletype radiation sensors are in the $\mu \mathrm{V}$-range, home-built amplifiers (electronic workshop, University of Bayreuth; amplification factors in Table 2) have been used to match the input sensitivity of the applied National Instruments DAQ device (range $0-1 \mathrm{~V}$ ). Each pair of radiation sensors is mounted on $40 \mathrm{~cm}$ long booms, which in turn are fixed on the front side of the HMMS's carrier platform, pointing in opposite directions but perpendicular to the driving direction (see Fig. 1). This lateral installation minimises "shadowing" effects caused by the HMMS itself and/or by the track's construction elements, and guarantees a rather free hemispheric view.

To measure the carbon dioxide concentration, the HMMS is equipped with a closed-path, single cell, non-dispersive infrared gas analyser (OEM Gascard ${ }^{\circledR} \mathrm{NG} \mathrm{CO}_{2}$, Edinburgh Instruments Ltd., Edinburgh, UK) with a fixed measurement range of $0-1000 \mathrm{ppm}$. The Gascard ${ }^{\circledR}$ NG is a very lightweight $(300 \mathrm{~g})$ and small $(160 \mathrm{~mm} \times 100 \mathrm{~mm} \times 40 \mathrm{~mm})$ sensor, an OEM version, which (a) has no housing (sheltered by the HMMS's Makrolon ${ }^{\circledR}$ cover only), and (b) is supplied by a small vacuum pump (12 V DC, $1.2 \mathrm{~L} \mathrm{~min}^{-1}$; model DC24/16F, Fürgut GmbH, Tannheim, Germany). The $\mathrm{CO}_{2}$ analyser's inlet tubing consists of an aluminium tube (inner dia. $3 \mathrm{~mm}$; outside of HMMS) and a flexible tube of polyethylene-aluminium composite structure (Dekabon, inner dia. $3 \mathrm{~mm}$; inside of HMMS). The overall length of inlet tubing is $50 \mathrm{~cm}$, which translates into a time delay $t_{\mathrm{D}}=0.2 \mathrm{~s}$. This has to be added to the delay caused by the time constant of the sensor. According to the manufacturer, the Gascard ${ }^{\circledR}$ NG's standard (optimised) response time should be $10 \mathrm{~s}\left(\tau_{90}\right)$. In our laboratory tests, we have determined a time constant $\tau_{63}$ with approx. $1 \mathrm{~s}$ for the Gascard ${ }^{\circledR}$ NG, including the delay time caused by inlet tubing length.

The ozone analyser (Zahn et al., 2012) applied on the HMMS has been developed by a cooperation between Karlsruhe Institute of Technology (Karlsruhe, Germany) and the company enviscope GmbH (Frankfurt, Germany). The analyser contains a fast response (up to $50 \mathrm{~Hz}$ ) photomultiplier measuring the chemiluminescence originating from a surface reaction of $\mathrm{O}_{3}$ with a coumarin dye layer on a small aluminium disc, which is in contact with the sample air stream. Enviscope $\mathrm{GmbH}$ provided an OEM version (without housing and front panel control elements), resulting in a $53 \%$ reduction of weight and $81 \%$ of volume without any loss of accuracy and performance. The second electrical circuit of the HMMS (see Sect. 2.1.1) provides the constant operating voltage for the analyser (12 V DC), while $24 \mathrm{~V} \mathrm{DC}$ power for heating of the reaction chamber (nominally 15-60 V DC) was tapped from the engines of the HMMS. A small vacuum pump (12 V DC, $3 \mathrm{~L} \mathrm{~min}^{-1}$; model DC24/80L; Fürgut Gmbh, Tannheim, Germany) is used to draw ambient air through the $\mathrm{O}_{3}$ analyser. Inlet tubing consisted of a $30 \mathrm{~cm}$ long black PTFE tube (inner dia. $6.35 \mathrm{~mm}$ ), similar to the first $10 \mathrm{~cm}$ of the outlet tubing. Another $20 \mathrm{~cm}$ of Dekabon tube (inner dia. $3 \mathrm{~mm}$ ) leads the output of the $\mathrm{O}_{3}$ analyser out through the bottom of the HMMS. In- and outlet tubing have to be black (lightproof), otherwise the (chemiluminescence) detection of $\mathrm{O}_{3}$ in the reaction chamber would be affected by incident sunlight. The chemiluminescence analyser was developed for aircraft and eddy covariance measurements at up to $50 \mathrm{~Hz}$; consequently its time constant is negligible and 
only the delay time of $0.5 \mathrm{~s}$, caused by the inlet tubing, has to be considered.

The (multiplier) raw signal of the enviscope $\mathrm{O}_{3}$ analyser (counts s ${ }^{-1}$ ) can be calibrated by a suitable $\mathrm{O}_{3}$ source. However, the sensitivity of the $\mathrm{O}_{3}$ analyser has a considerable temporal variability caused by the aging of the sensor's disc within 2 days (Zahn et al., 2012). Therefore, the signal of the $\mathrm{HMMS}_{3}$ analyser was adjusted in situ by simultaneous $\mathrm{O}_{3}$ concentration measurements performed at a fixed location $0.5 \mathrm{~m}$ lateral to the HMMS track at the turning point of the HMMS in the forest (see Fig. 2, label "49i"). Every time the HMMS passed this point, the fast-response $\mathrm{O}_{3}$ analyser at the HMMS was adjusted to the $\mathrm{O}_{3}$ monitor (approx. every $10 \mathrm{~min}$ ). These measurements were performed by a commercial state-of-the-art $\mathrm{UV}$-absorption $\mathrm{O}_{3}$ analyser (Thermo Instruments, model 49i; MLU GmbH, Mödling, Austria).

\subsection{Correction of sensor response time induced spatial errors}

The input signal of most sensors will follow a very sudden change in the measured quantity with certain delay and damping effects. These effects are commonly characterised by an individual sensor response time, or time constant. The bias is usually due to (a) the sensor itself, (b) the sensor's housing, and/or (c) the sensor's inlet system, particularly for gas analysers (see Mayer et al., 2009). The signal's temporal adaptation of so-called first-order measuring systems to a sudden temporal change of the quantity to be measured can be described in the following form (e.g. Brock and Richardson, 2001; Foken, 2008):

$X_{\mathrm{o}}(t)=X_{\mathrm{i}}(t)+\tau \frac{\mathrm{d} X_{\mathrm{i}}}{\mathrm{d} t}$,

where $\tau$ is the time constant and $t$ stands for the time. The time constant $\tau$ characterises the dependency between the input signal $X_{\mathrm{i}}$ and the output signal $X_{\mathrm{o}}$, in other words the inertia of the sensor and/or the measuring system, respectively. Equation (1) has the following exponential solution:

$X(t)=X_{\infty}\left(1-e^{-\frac{t}{\tau}}\right)$,

where $X_{\infty}$ is the final value of $X(t)$ after final adaptation to new conditions.

The time constant of a sensor is of much greater importance for mobile measuring systems than it is for standard tower and other stationary measuring systems. The movement of the measuring system means that the time constant can result in an error in time and also in space. The total error of a measuring system is referred to as the dynamical error. A linear change in a measured quantity is achieved when

$X_{\mathrm{i}}(t)=0$ for $t \leq 0$

and

$X_{\mathrm{i}}(t)=a \cdot t \quad$ for $\quad t>0$ with $a$ as a constant and $X(0)=0$ as the initial conditions. This leads to a change of Eq. (1):

$a \cdot t=X_{\mathrm{i}}(t)+\tau \frac{\mathrm{d} X_{\mathrm{i}}}{\mathrm{d} t}$.

The exponential solution is

$X(t)=a \cdot t-a \cdot \tau\left(1-e^{-\frac{t}{\tau}}\right)$.

The dynamical error can be defined as the second term in the right-hand side of Eq. (6). There are possibilities to correct the dynamical error mathematically and these corrections were done mainly for temperature sensors in aircraft (e.g. Rodi and Spyers-Duran, 1972; McCarthy, 1973; Friehe and Khelif, 1992; Inverarity, 2000; Saggin et al., 2001). Correction algorithms also exist for the temperature and humidity measurements with radiosondes (e.g. Miloshevich et al., 2004), while another linear correction algorithm for temperature sensors in a vertical moving platform was developed by Mayer et al. (2009). Comparable corrections for measurements with horizontal measuring systems (named in Sect. 1) have not yet been made, because of (a) an averaging along the measuring track (especially for radiation measurements in more homogeneous measuring sites), (b) a nonmoving system while measurements are conducted, to guarantee a full adaptation of the sensor input signal to the prevailing environmental conditions and (c) the application of high-frequency sensors for which the dynamical errors are negligible. The measured values of the HMMS had to be corrected, because we (a) had a heterogeneous measuring site, with the focus on a forest edge (not suitable for averaging), (b) would have lost too many details with non-moving measurements and (c) had weight and money restrictions, so we had to abandon the application of high-frequency sensors (apart from the $\mathrm{O}_{3}$ analyser).

\subsection{Site description and application of HMMS}

The first field application of the HMMS was during the EGER IOP3 project in June and July 2011 at the Waldstein-Weidenbrunnen site $\left(50^{\circ} 08^{\prime} 31^{\prime \prime} \mathrm{N}, 11^{\circ} 52^{\prime} 01^{\prime \prime} \mathrm{E}\right.$, $775 \mathrm{~m}$ a.s.1.). It is a research site of the Bayreuth Center of Ecology and Environmental Research (BayCEER), and is located in the Lehstenbach catchment, part of the Fichtelgebirge Mountains (northeastern Bavaria, Germany). The site is also a FLUXNET site (DE-Bay, Baldocchi et al., 2001), where $\mathrm{CO}_{2}$ flux measurements above a dense spruce forest have been conducted since 1996. Detailed information about the site can be found in Gerstberger et al. (2004), as well as in Staudt and Foken (2007). The research site is dominated by Norway Spruce trees of $27 \mathrm{~m}$ canopy height (as of 2011). On 18 January 2007, the "hurricane like" low-pressure system "Kyrill" destroyed large areas of the dense spruce forest, including areas close to the research site (in a southerly direction). Meanwhile, the clearing's vegetation is similar 


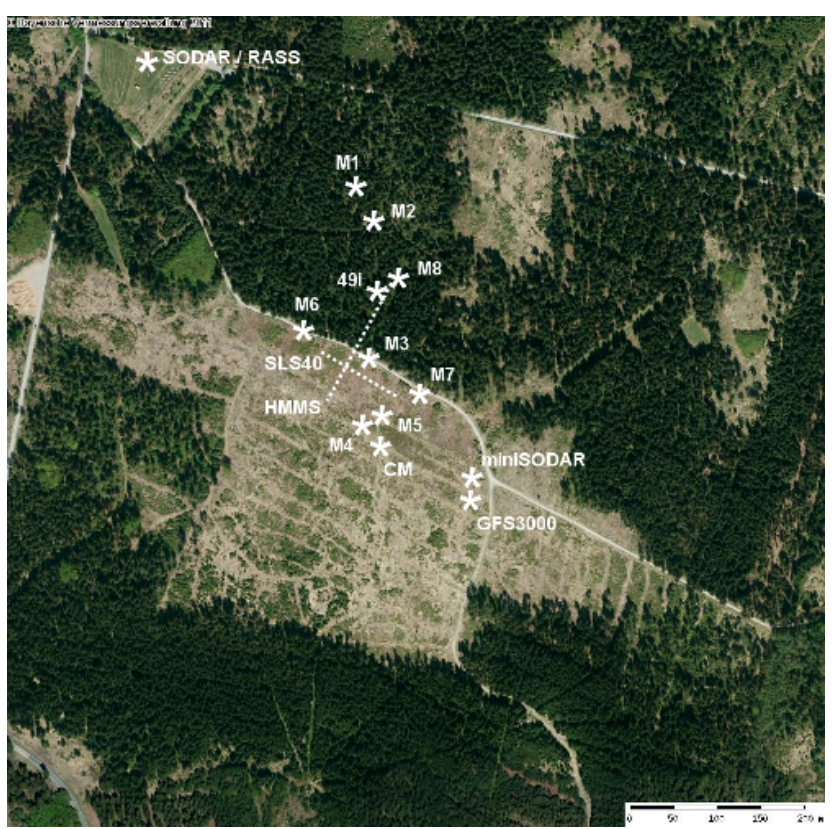

Figure 2. Top view of the investigation site of the EGER IOP3 project in summer 2011, with all measuring points and exact positions of the main tower M1 $(32 \mathrm{~m})$, the turbulence tower M2 $(36 \mathrm{~m})$, the forest edge tower M3 $(41 \mathrm{~m})$, the turbulence mast M4 $(5.5 \mathrm{~m})$, the mast for the Modified Bowen-Ratio Method M5 $(3.1 \mathrm{~m})$, the turbulence masts M6-M8 $(5.5 \mathrm{~m})$, the mast for chemical measurements CM (2 m), the Laser-Scintillometer SLS40, the Horizontal Mobile Measuring System HMMS, the ozone monitor "49i", SODAR/RASS, miniSODAR, and the GFS3000 (leaf gas exchange measurements). The map is oriented to the north. Aerial image taken from Bayerische Vermessungsverwaltung, URL: http://geoportal.bayern.de/bayernatlas?base=910.

to the understorey of the forest: grass, fern, bushes (mainly blueberries), young spruces (1-2 m), and deadwood. The scientific focus of EGER IOP3 were diel cycles of energy, water and trace gases of the soil-vegetation-atmosphereboundary-layer system of this disturbed forest ecosystem. To investigate the forest edge's impact on the exchange processes, turbulence flux tower measurements were performed at the clearing, at the forest edge, and within and above the forest (see Fig. 2; more details in Serafimovich et al., 2011).

In addition to these locally fixed towers, the $150 \mathrm{~m}$ long measuring track of the HMMS was built in a NNE to SSW direction, perpendicular to the forest edge $(75 \mathrm{~m}$ in the forest and the clearing, respectively). The track is marked by the dotted line (labelled HMMS) in Fig. 2. The elevation difference between start (forest) and end (clearing) point of the HMMS track was approx. $-8 \mathrm{~m}\left(-5 \%\right.$, or $\left.-3^{\circ}\right)$. Applying a sampling frequency of $1 \mathrm{~Hz}$, the HMMS ran with a quasi-constant speed of $0.5 \mathrm{~m} \mathrm{~s}^{-1}$ approx. $1 \mathrm{~m}$ above ground. The HMMS was usually started in the forest, where the $\mathrm{O}_{3}$ concentration was continuously monitored by the $\mathrm{O}_{3}$ monitor Thermo Instruments, model 49i (see Fig. 2, label "49i”). For a complete reverse run $(300 \mathrm{~m}$; forest-clearingforest) the HMMS needed approx. $10 \mathrm{~min}$.

Taking into account appropriate weather conditions and the main project issues, almost $250 \mathrm{~h}$ of data were collected during various daytime and night-time periods within the 6 weeks of EGER IOP3.

\section{Results and discussion}

By means of laboratory tests we determined the individual time constant $\tau_{63}$ for most sensors used on the HMMS. The results of the laboratory tests are presented in Sect. 3.1.

Following this, we want to present results from 28 June 2011. There was an almost cloudless sky and, due to preceding dry weather conditions high air temperatures and low humidities also prevailed. Low humidities during nighttime $(<90 \%)$ led to the absence of early morning fog and dew. The time series of HMMS were nearly complete during 28 June. Unfortunately, the time series of the ozone concentration reveals larger gaps due to connection problems of the $\mathrm{O}_{3}$ analyser. We present the application of the correction algorithm (Sect. 3.2), radiation-induced errors in $\mathrm{CO}_{2}$ concentration measurements (Sect. 3.3) and diurnal variations in all measured quantities (Sect. 3.4).

\subsection{Sensor response time determination}

A detailed knowledge about the individual sensor response time is unavoidable if the response-time-induced dynamical errors are to be properly corrected. We therefore conducted laboratory tests, re-positioning the HMMS very quickly $(<1 \mathrm{~s})$ in two different environments possessing different conditions. This was carried out for temperature and humidity by relocating between a large cold chamber and constant environmental conditions in a room, for long-wave radiation above two water bodies with different temperatures and for short-wave radiation with and without short-wave light. The $\mathrm{CO}_{2}$ analyser was tested between nitrogen and a $\mathrm{CO}_{2}$ calibration gas. A laboratory test for the $\mathrm{O}_{3}$ analyser was not necessary because of the low time constant.

Table 3 gives the exact numbers obtained with the sudden change of the environmental conditions. The signal differences were used for the calculation of the time constant $\tau_{63}$, which indicates a change of the signal of $63 \%$ of the final value (Fig. 3). For a better comparison, the signal difference is presented as the normalised difference between the initial value $(0.0)$ and the final value (1.0). The calculation also served for the identification of possible hysteresis effects, which were found for the temperature and humidity sensor. For both sensors, the adaptation to changes in the input signal was faster for a positive signal difference ( $T$ : cold $\rightarrow$ warm; RH: dry $\rightarrow$ wet).

A value close to the final signal is measured after a sudden change of the input signal beyond five times the time constant 


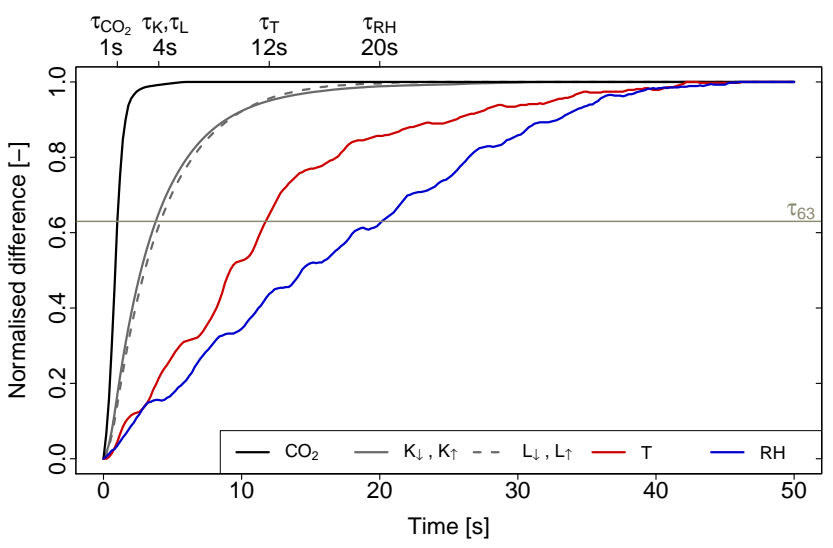

Figure 3. Measurement results of the laboratory tests of the time constant $\tau_{63}$. The small fluctuations of the temperature and humidity signal are caused by the turbulence under room conditions. An overview of all sensors is given in Tables 2 and 3 .

(Foken, 2008). This delay causes, together with the speed of the HMMS $\left(0.5 \mathrm{~m} \mathrm{~s}^{-1}\right)$, a spatial relocation of the measurement signal. The calculated values for the spatial relocation can be found in Table 3. The relocation for the sensors with an identified hysteresis can vary, depending on the way the change in the input signal occurs. This relocation can be corrected with the correction algorithm (see section below) or must be taken into account for the interpretation of the data.

\subsection{Application of the correction algorithm}

The main focus of this work is, besides the technical presentation of the HMMS together with the exact determination of the individual response times, the inspection of the measured quantities. Here, the focus lies mainly on the forest edge: the transition area from the dense spruce forest to the open clearing (this transition area, and not the dense forest or the open clearing, is also the focus of all further investigations in the EGER IOP3 project). An abrupt change in the input signals of all quantities is observable mostly within a few metres distance of the forest edge. Because of the individual sensor response times and the motion of HMMS, the measured input signals lag behind the "true" input signal.

To correct the lag, or rather the dynamical errors in the measurements of the HMMS sensors, we use a correction algorithm of the recorded signal $X_{i}$ with a linear adjustment after Eq. (6), a first-order differential equation. However, we are aware that at the measuring site, especially at the forest edge, the prevailing gradients are influenced by turbulence, with an increased number of coherent structures like sweeps and ejections (Eder et al., 2013), and also by smallscale heterogeneities. Within a short time, these structures can have an effect on the gradient, which leads to an overlapping of several different functions and to non-steady-state conditions. There is, for example, a generalised dynamic performance model (Brock and Richardson, 2001), which

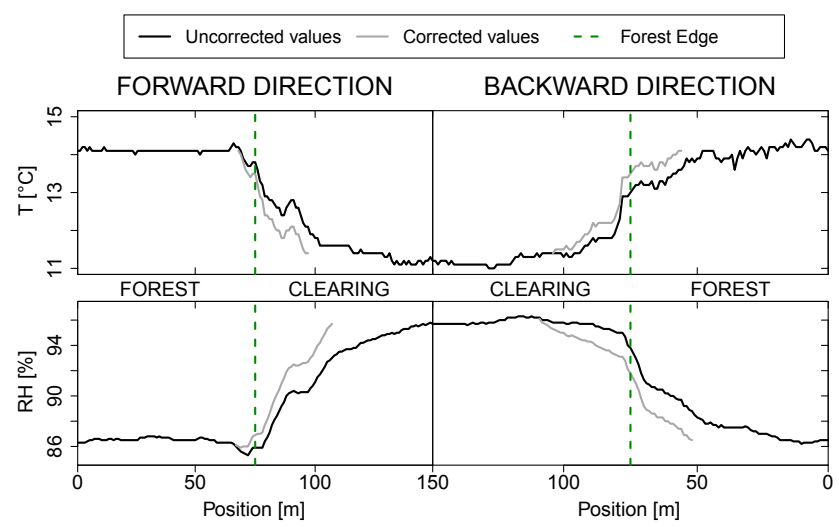

Figure 4. Example time series of temperature (top) and relative humidity (bottom) for one complete run of the HMMS during nighttime of 28 June 2011. The runtime was 02:53-02:58 CET in the forward direction and 02:58-03:03 CET in the backward direction. The forest edge is indicated by the vertical green dotted line. The time series shows the uncorrected measured values (black solid line) and, at the forest edge, the corrected gradient (grey solid line).

considers - beside a steady-state solution - a transient solution. Nevertheless, we confined ourselves to the correction algorithm which includes a linear adjustment, since the changes in the quantities caused by the transition from the forest to the clearing are significantly higher than the changes caused by fluctuations of small-scale structures, which have a purely random character.

For the correction, we examined the time series individually for every single run of the HMMS (forest to clearing, or back) and determined the starting point and the endpoint of the significant change and the gradient itself near the forest edge. Afterwards we corrected the measured values to the "true" measured values. After the correction, the final value of the signal will be reached earlier in time and also in spatial terms. The investigation of many runs showed us that this procedure is the best way to correct the measured values along the forest edge.

Because of the necessity of an individual determination of the linear function, we decided to correct only that data of measurements which are used for detailed studies of the micrometeorological phenomena near the forest edge. In the following we present two examples of the correction algorithm, and in Sect. 3.4 a daily cycle of all parameters which has not been corrected. Due to a lower spatial resolution of the figures the general information is not disturbed.

Figure 4 shows a night-time series for air temperature (top) and relative humidity (bottom) of one complete run of the HMMS. The run led from the forest to the clearing ("Forward Direction" - 02:53-02:58 CET) and from the clearing back to the forest ("Backward Direction" - 02:58-03:03 CET). In the forest and in the clearing, measured (uncorrected) values (black solid lines) were almost constant, while near the forest edge there was an obvious steep gradient. For this case, the 

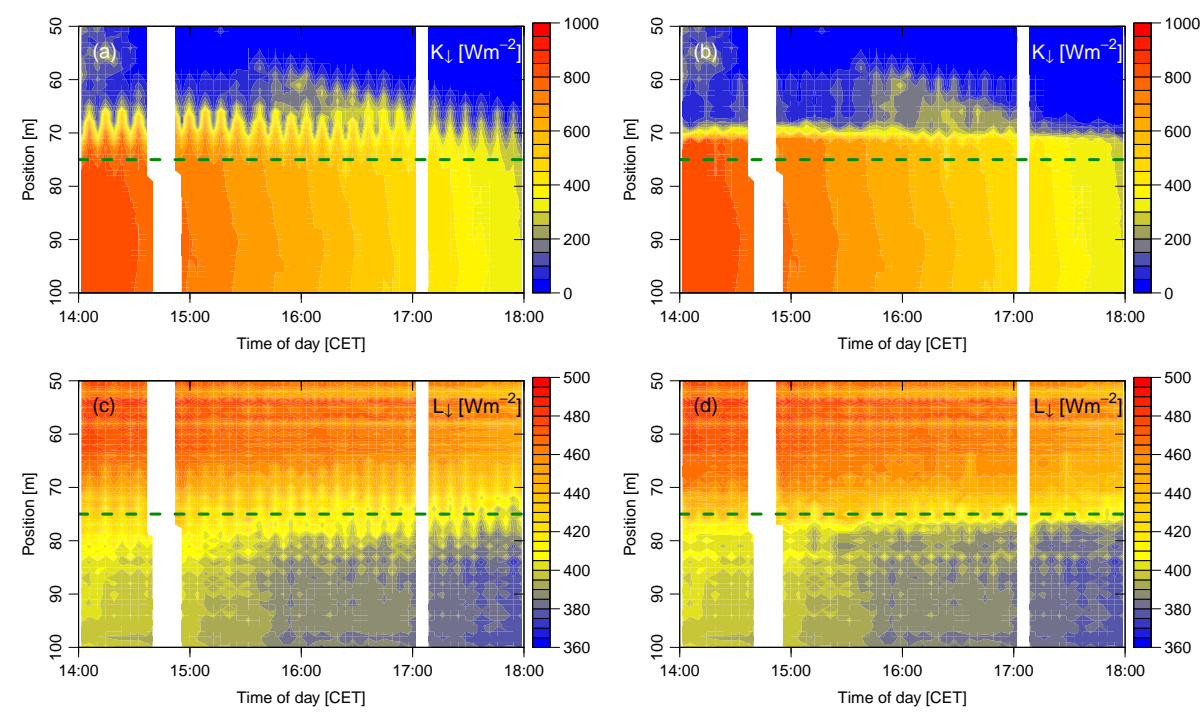

Figure 5. Detailed horizontal profiles during daytime of 28 June 2011 at the forest edge (horizontal green dotted line), uncorrected profiles for short-wave downwelling radiation $K_{\downarrow}$ (a) and long-wave downwelling radiation $L_{\downarrow}$ (c), and in both cases response time corrected profiles (b, d). Position shows distance from starting point in metres, starting in the forest $(50 \mathrm{~m})$ and ending at the clearing $(100 \mathrm{~m})$.

starting points and the endpoints of the respective in/decrease of the corresponding quantity were determined individually by visual inspection.

The grey lines in Fig. 4 indicate the corrected data of air temperature and relative humidity at the forest edge. They clearly show that a correction of the measured values is required in order to interpret the results of the measurements correctly. The relocation of the measured signal compared to the corrected measured signal is obvious and corresponds to the calculated relocation in Table 3. After the correction the "true" measured values for air temperature have almost the same values at the forest edge, while the gradient for the relative humidity starts in the backward direction much later than in the forward direction. Possible reasons could be (a) an effect caused by the hysteresis or (b) an abrupt change of the gradient affected by turbulent structures, or (c) a combination of both effects.

Figure 5 shows horizontal profiles of short-wave downwelling radiation $\left(K_{\downarrow}\right)$ and long-wave downwelling radiation $\left(L_{\downarrow}\right)$ during daytime of the 28 June around the forest edge. The significant change of $K_{\downarrow}$ (top) occurred approximately $5 \mathrm{~m}$ north of the forest edge (position measured from starting point: $70 \mathrm{~m}$ ) because the sun was shining into the first metres of the forest's understorey. In contrast, the significant change of $L_{\downarrow}$ (bottom) lies exactly on the forest edge (position measured from starting point: $75 \mathrm{~m}$ ). The profiles in Fig. $5 \mathrm{a}$ and c show the uncorrected measurements for $K_{\downarrow}$ and $L_{\downarrow}$, respectively. Time constants of the sensors and the different driving direction of the HMMS led to the zigzag pattern of the uncorrected measurement data. To correct radiation measurements between 14:00 and 18:00 CET of 28 June 2011, we considered corresponding response times ( $4 \mathrm{~s}$, see Table 3$)$, defined starting and end points of the linear gradient and calculated the "true" data assuming a linear gradient of radiation data between starting and end point. The dynamical error corrected horizontal radiation profiles, shown in Fig. $5 \mathrm{~b}\left(K_{\downarrow}\right)$ and $5 \mathrm{~d}\left(L_{\downarrow}\right)$, are nearly free of the zig-zag pattern.

\subsection{Radiation-induced error in $\mathrm{CO}_{2}$ measurements}

Due to the small time constants $\left(\tau_{63}<1 \mathrm{~s}\right.$, see Table 3$)$, there is no need for a response-time-induced error correction of the $\mathrm{CO}_{2}$ and $\mathrm{O}_{3}$ measurements. Whereas the $\mathrm{O}_{3}$ measurements, which - with the exception of the mentioned connection problems - were of high accuracy, we observed substantial problems in the $\mathrm{CO}_{2}$ measurements during daytime. $\mathrm{Be}$ cause of a late delivery of the $\mathrm{CO}_{2}$ analyser shortly before the start of the project, we had no chance to check the analyser against different influences. Laboratory tests after the project have shown that the $\mathrm{CO}_{2}$ concentration can be kept at a constant level as long as the analyser is not exposed to direct sunlight, and immediately drifts down if the analyser is subjected to direct sunlight. Because of this we had to discard the $\mathrm{CO}_{2}$ measurements during daytime, whereas the measured values recorded during night-time coincide with other $\mathrm{CO}_{2}$ measurements near the HMMS track. Since larger spatial differences in $\mathrm{CO}_{2}$ measurements occur mainly during night-time, this is not a significant limitation in the applicability of the HMMS system. However, in subsequent projects we should consider the use of a different analyser.

\subsection{Measurement results with HMMS}

In Fig. 6, results of the HMMS for 28 June 2011 are shown. There are complete horizontal profiles $(150 \mathrm{~m}-$ starting in 

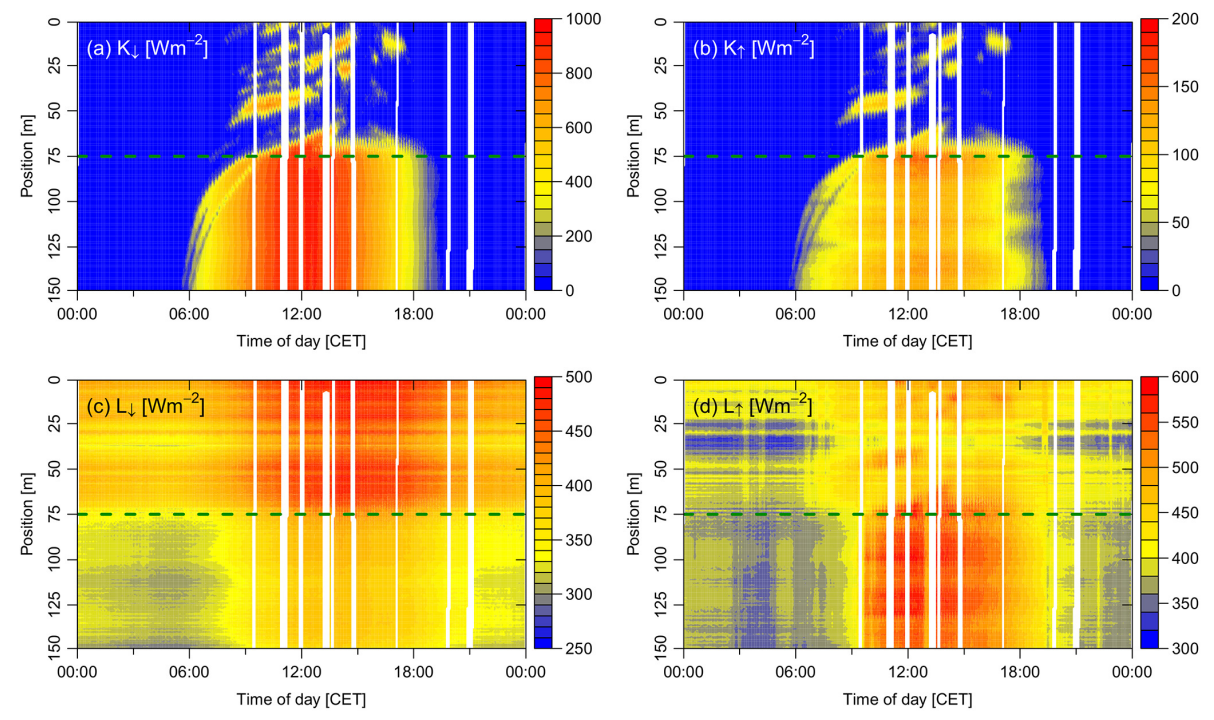

Figure 6. Complete horizontal profile for the whole of 28 June 2011 for all measured quantities. (a) shows the downwelling short-wave radiation $\left(K_{\downarrow}\right)$ and (b) the upwelling short-wave radiation $\left(K_{\uparrow}\right)$. (c) shows the downwelling long-wave radiation $\left(L_{\downarrow}\right)$ and (d) the upwelling long-wave radiation $\left(L_{\uparrow}\right)$. Remark: the scaling of the four radiation components is different in the four graphs. Position shows distance from the starting point in metres, with the starting point in the forest $(0 \mathrm{~m})$, forest edge $(75 \mathrm{~m}$, horizontal green dotted line) and endpoint at the clearing $(150 \mathrm{~m})$.

the forest and ending at the clearing - with the forest edge, indicated by a green dotted line, in the middle of the HMMS track) focusing on the daily cycles for each measured quantity. As we mentioned above, we are not able to show a complete corrected time series of the measured quantities (regarding the time constant) because of the large effort required for the individual determination of the linear function of every single run. The profiles therefore show the values as measured, without correction to take into account the time constant. For the inspection and interpretation of the daily variations along the transect forest-clearing, the uncorrected profiles are sufficient.

The short-wave radiation components $K_{\downarrow}$ and $K_{\uparrow}$ (Fig. 6a and b) are very low in the forest, but sunny spots can be seen at different locations and times. In the morning the shadow of the forest edge can be seen beginning at 05:30 CET on the complete clearing, decreasing from run to run. At 08:30 CET the sunlight on the clearing is no longer influenced by the forest edge. As well, the HMMS itself has an influence on the measurements in the morning hours because of the sensor location on the sun-shaded side. This behaviour starts at 06:00 CET and after 09:00 CET this effect disappears.

During the day the long-wave downwelling radiation $L_{\downarrow}$ (Fig. 6c) in the forest is almost the same as the long-wave upwelling radiation $L_{\uparrow}$ (Fig. 6d) at the clearing. So the surface temperature at the clearing is almost the same as the temperature of the top of forest canopy. In the night, the clearing shows significantly lower values for $L_{\uparrow}$ than in the forest. Only where the forest canopy has open areas (see the sunny spots in short-wave radiation measurements), is $L_{\uparrow}$ in the forest almost the same as $L_{\uparrow}$ at the clearing.
In Fig. 6e the complete horizontal profile for the temperature is shown. The lowest temperatures occur during nighttime and the highest during daytime at the clearing. The increase of temperature in the morning starts at the clearing significantly earlier than in the forest. And also the decrease in the evening starts earlier at the clearing.

The relative humidity (Fig. 6f) is, at night-time, higher on the clearing than in the forest and at daytime this is reversed. The decrease after the sunrise is significantly earlier at the clearing than in the forest. Also, the increase in the evening starts earlier at the clearing.

The $\mathrm{CO}_{2}$ concentration (Fig. $6 \mathrm{~g}$ ) has its maximum in the early morning and early evening under very stable situations. This in is accordance with the findings of Foken et al. (2012) and Serafimovich et al. (2011). They found a concentration accumulation during uncoupled situations. Here the higher values are at the clearing, and also during night-time the higher values can be found at the clearing. The variations/lower concentrations around 21:00 CET are caused by a change in the wind direction from northerly to easterly winds and the advection of colder/ $\mathrm{CO}_{2}$-depleted air. Because of the radiation-induced errors in the $\mathrm{CO}_{2}$ concentration measurements, we have shown only measured values during night.

Unfortunately there are bigger gaps in the profile of the $\mathrm{O}_{3}$ concentration (Fig. 6h), due to the mentioned connection problems, but the increase in the afternoon is still clearly visible, with a significant gradient between forest and clearing. This is certainly the result of the good weather conditions during this day, as the ozone formation is mainly a suninduced photochemical reaction. 

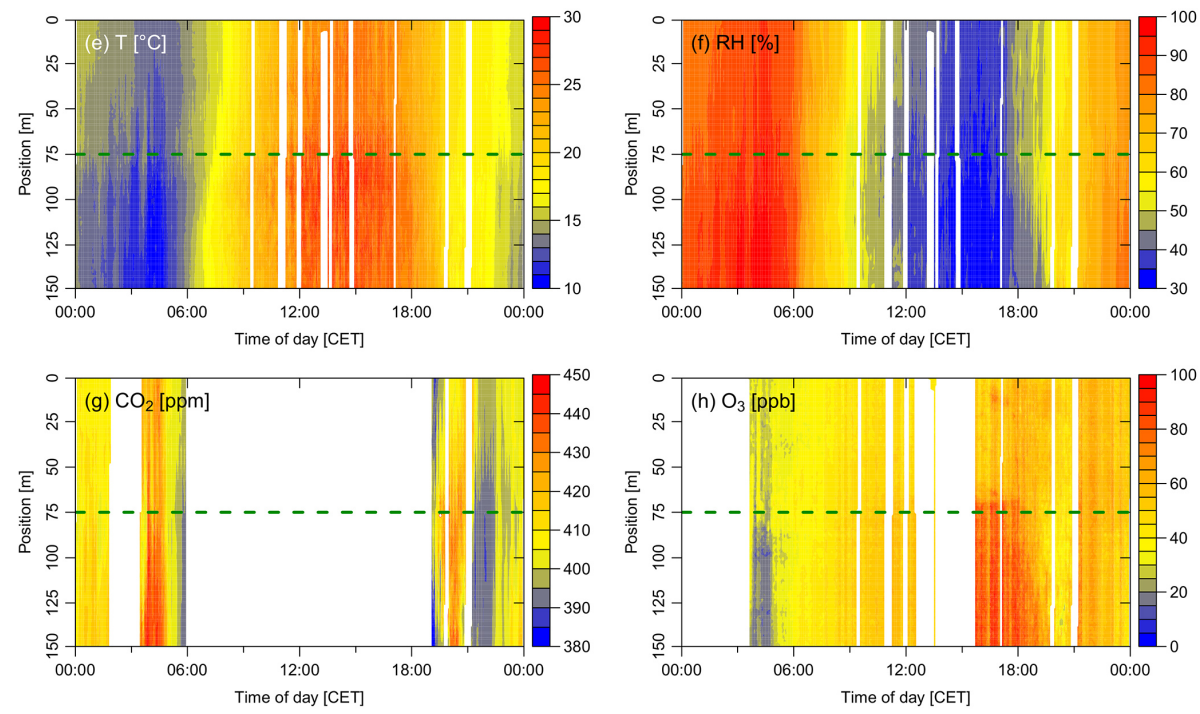

Figure 6. (Continued) Complete horizontal profile for the whole of 28 June 2011 for all measured quantities. (e) shows the temperature (T) and (f) the relative humidity $(\mathrm{RH})$. (g) shows the carbon dioxide concentration $\left(\mathrm{CO}_{2}\right)$ and (h) the ozone concentration $\left(\mathrm{O}_{3}\right)$. Position shows distance from the starting point in metres, with starting point in the forest $(0 \mathrm{~m})$, forest edge $(75 \mathrm{~m}$, horizontal green dotted line $)$ and endpoint at the clearing $(150 \mathrm{~m})$.

\section{Conclusions}

Regarding the technical aspects of the HMMS, we can affirm that the drive mechanism with the garden railway system was uncomplicated in terms of the system integration and the control by the HMMS software, and also the application during dry conditions was uncomplicated. In spite of that, we had several problems with the rail system during the project: under wet conditions the climbing ability of the HMMS was lost; however measurements had to be stopped under these conditions anyway, because of the insufficient waterproofness. And the relatively high coefficient of thermal expansion of brass caused problems in the smooth driving of the HMMS. While during temperatures above $20^{\circ} \mathrm{C}$ wave formations in the total rail system could be observed, leading to a halting system, there were during night and early morning (cold temperatures, $T<10^{\circ} \mathrm{C}$ ) gaps between the $2 \mathrm{~m}$ long rail segments observable. If the gap occurred in the first $25 \mathrm{~m}$ (Position: 0 to $25 \mathrm{~m}$ ) or in the last $25 \mathrm{~m}$ (Position: 125 to $150 \mathrm{~m}$ ), this led to powerless rail segments and a stopped HMMS system, due to the chosen feed points for the power (see Sect. 2.1.1). Those problems led to a high variability in the durations for a single run of the HMMS. During a subsequent project with the HMMS, which was conducted in summer 2012, we used modified connectors between the rail segments, which resulted in a significant improvement in the rail system. And also a feed-in of power up to the end was used to avoid powerless rail segments. Regarding the drive mechanism (here: especially the inner workings of the engines) we were surprised that the engines kept up the $250 \mathrm{~h}$ of operating time during EGER IOP3 and that maintenance was only necessary after the end of the project. But an ageing of the engines was already observable over time, which resulted in longer run duration times. We had expected a substantially shortened lifespan of the engines, because the total weight of the HMMS was almost 10 times greater than the original weight of the garden railway locomotive, resulting in a higher axial load and consequently more stress for the engines. A more robust drive system, like e.g. Oncley et al. (2009) used (with cables and steel wheels) is certainly more uncomplicated in terms of consistency and durability, but on the other hand the development effort and financial input is substantially larger.

The set of devices, used for the control of the HMMS, as well as the data acquisition was nearly unproblematic. The HMMS software was together with the DAQ device a perfect interface between the sensors and the data acquisition and also between the determination of position (bar codes) and the HMMS speed and driving direction system. Only the bar code scanner had during humid conditions (morning fog) some intermittent failed readings, because of dew on the codes and the sensor's glass, and during sunny days the scanner had to be shadowed to avoid failed readings.

In the case of the sensor system on the HMMS, most of the sensors (CMP3/CGR3, HMP155, $\mathrm{O}_{3}$ analyser) are frequently used in meteorological measurements and as a consequence, the application was quite simple and the results were adequate. Because of the low accuracy $( \pm 40 \mathrm{ppm})$ and the radiation induced errors in the $\mathrm{CO}_{2}$ concentration measurements, we should consider a change to a more accurate sensor, or protect the sensor with a housing and a cooling system. This could in turn lead to high demands being placed on the power 
supply of the HMMS. Here, perhaps the change from a transparent to a non-transparent Makrolon ${ }^{\circledR}$ cover could be a sufficient remedy. We chose the transparent cover only for an easy view into the HMMS system.

The focus of this work was the description of the HMMS system and the correction algorithm, and to show first results of the measurements. Those show a clear gradient near the forest edge, as we expected. The application of the correction algorithm shows a more significant gradient within a shorter distance. So the before-and-after comparisons illustrate the need for the correction algorithm, especially for the slow responding sensors. The results of the correction algorithm are, for most cases, absolutely sufficient. Without these corrections it is not possible to investigate the processes near the forest edge very well. Especially in the turbulence influenced quantities (temperature, humidity and trace gas concentrations), we can find significant changes in the gradients at the forest edge within a short period of time. So we can assume that these gradients are influenced by turbulence structures near the forest edge (and also the first metres of the forest and the clearing), while the influence decreases both into the forest and into the clearing, until the measurements are almost unaffected by the forest edge.

Combined with turbulence measurements, the HMMS is a good tool for a better understanding of the exchange processes near the forest edge. Besides the investigation of the forest edge, we get an overview of this heterogeneous forest ecosystem not possible if static tower measurements were to be used instead of the HMMS. As with every mobile measuring system, the HMMS has the limitation that it cannot measure at every location simultaneously. The HMMS can therefore never replace tower measurements, otherwise we would lose information about small-scale and short-time events. Our research now goes in two directions: (a) the investigation of the heterogeneity of scalars in combination with the results found in Foken et al. (2012) and (b) the influence of coherent structures on horizontal structures according to the findings of Eder et al. (2013).

Acknowledgements. The full functionality and the fast construction of the HMMS would not have been possible without the support of the technical workshops of the University of Bayreuth. We would like to thank the company enviscope $\mathrm{GmbH}$, and in particular H. Franke and C. Klaus, for their fast ozone analyser, which they lent us for the EGER IOP3 project in summer 2011. In particular, their modifications for a smaller and lighter ozone analyser made it possible to measure ozone gradients with the HMMS. We also want to thank the company SICK Vertriebs-GmbH, in particular M. Clement, for the gift of the bar code scanners, and we are also grateful for his fast support. Furthermore, we would like to thank L. Heymann from the Chair of Applied Mechanics and Fluid Dynamics from the University of Bayreuth, who helped us determine the flow rate inside the radiation-shielded tube of the HMP155. Qianqian Liu helped us manage the measurements with the HMMS during the project. And we want to thank all other PhD students of the Department of Micrometeorology, student assistants and G. Müller from BayCEER for helping us with the construction of the wooden substructure of the HMMS track.

The EGER IOP3 project was funded by the German Science Foundation (DFG) under the contract numbers DFG projects: PAK 446 (FO 226/21-1, ME 2100/5-1, RA 617/23-1 and HE 5214/4-1). The funding of the HMMS was realised by the University of Bayreuth and the Max Planck Institute for Chemistry, but not within PAK 446. This publication is funded by the German Research Foundation (DFG) and the University of Bayreuth in the funding programme Open Access Publishing.

Edited by: U. Friess

\section{References}

Assmann, R.: Das Aspirationspsychrometer, ein neuer Apparat zur Ermittlung der wahren Temperatur und Feuchtigkeit der Luft, Das Wetter, 4, 245-286, 1887.

Assmann, R.: Das Aspirationspsychrometer, ein neuer Apparat zur Ermittlung der wahren Temperatur und Feuchtigkeit der Luft, Das Wetter, 5, 1-22, 1888.

Baldocchi, D., Hutchison, B., Matt, D., and McMillen, R.: Seasonal variations in the radiation regime within an oak-hickory forest, Agr. Forest Meteorol., 33, 177-191, doi:10.1016/01681923(84)90069-8, 1984a.

Baldocchi, D. D., Matt, D. R., Hutchison, B. A., and McMillen, R. T.: Solar radiation within an oak-hickory forest: an evaluation of the extinction coefficients for several radiation components during fully-leafed and leafless periods, Agr. Forest Meteorol., 32, 307-322, doi:10.1016/0168-1923(84)90056-X, 1984b.

Baldocchi, D., Falge, E., Gu, L., Olson, R., Hollinger, D., Running, S., Anthoni, P., Bernhofer, C., Davis, K., Evans, R., Fuentes, J., Goldstein, A., Katul, G., Law, B., Lee, X., Malhi, Y., Meyers, T., Munger, W., Oechel, W., Paw U, K. T., Pilegaard, K., Schmid, H. P., Valentini, R., Verma, S., Vesala, T., Wilson, K., and Wofsy, S.: FLUXNET: A new tool to study the temporal and spatial variability of ecosystemscale carbon dioxide, water vapor, and energy flux densities, B. Am. Meteorol. Soc., 82, 2415-2434, doi:10.1175/15200477(2001)082<2415:FANTTS>2.3.CO;2, 2001.

Balsley, B. B., Baisley, C. L., Williams, J. B., and Tyrrell, G. W.: Atmospheric research using kites: here We Go Again!, B. Am. Meteorol. Soc., 73, 17-29, doi:10.1175/15200477(1992)073<0017:ARUKHW>2.0.CO;2, 1992.

Balsley, B. B., Jensen, M. L., and Frehlich, R. G.: The use of stateof-the-art kites for profiling the lower atmosphere, Bound.-Lay. Meteorol., 87, 1-25, doi:10.1023/A:1000812511429, 1998.

Bentley, J. P.: Principles of measurement systems, Pearson Prentice Hall, Harlow, 2005.

Blanken, P. D., Black, T. A., Neumann, H. H., den Hartog, G., Yang, P. C., Nesic, Z., and Lee, X.: The seasonal water and energy exchange above and within a boreal aspen forest, J. Hydrol., 245, 118-136, doi:10.1016/S0022-1694(01)00343-2, 2001.

Brock, F. V. and Richardson, S. J.: Meteorological Measurement Systems, Oxford University Press, New York, 2001.

Brown, G. W.: Measuring transmitted global radiation with fixed and moving sensors, Agr. Meteorol., 11, 115-121, doi:10.1016/0002-1571(73)90055-1, 1973. 
Chen, J., Franklin, J. F., and Spies, T. A.: Contrasting microclimates among clearcut, edge, and interior of old-growth Douglasfir forest, Agr. Forest Meteorol., 63, 219-237, doi:10.1016/01681923(93)90061-L, 1993.

Chen, J., Franklin, J. F., and Spies, T. A.: Growing-season microclimatic gradients from clearcut edges into old-growth douglas-fir forests, Ecol. Appl., 5, 74-86, doi:10.2307/1942053, 1995.

Chen, J. M., Blanken, P. D., Black, T. A., Guilbeault, M., and Chen, S.: Radiation regime and canopy architecture in a boreal aspen forest, Agr. Forest Meteorol., 86, 107-125, doi:10.1016/S0168-1923(96)02402-1, 1997.

Dabberdt, W. F.: Tower-induced errors in wind profile measurements, J. Appl. Meteorol., 7, 359-366, doi:10.1175/15200450(1968)007<0359:TIEIWP>2.0.CO;2, 1968.

Davies-Colley, R. J., Payne, G. W., and van Elswijk, M.: Microclimate gradients across a forest edge, New Zeal. J. Ecol., 24, 111-121, 2000.

Dawson, J. W. and Sneddon, B. V.: The New Zealand lowland rainforest. A comparison with tropical rainforest, Pac. Sci., 23, 131$147,1969$.

Dupont, S., Bonnefond, J.-M., Irvine, M. R., Lamaud, E., and Brunet, Y.: Long-distance edge effects in a pine forest with a deep and sparse trunk space: in situ and numerical experiments, Agr. Forest Meteorol., 151, 328-344, doi:10.1016/j.agrformet.2010.11.007, 2011.

Eder, F., Serafimovich, A., and Foken, T.: Coherent structures at a forest edge: properties, coupling and impact of secondary circulations, Bound.-Lay. Meteorol., 148, 285-308, doi:10.1007/s10546-013-9815-0, 2013.

Foken, T.: Micrometeorology, Springer-Verlag, Heidelberg, 2008.

Foken, T., Meixner, F. X., Falge, E., Zetzsch, C., Serafimovich, A., Bargsten, A., Behrendt, T., Biermann, T., Breuninger, C., Dix, S., Gerken, T., Hunner, M., Lehmann-Pape, L., Hens, K., Jocher, G., Kesselmeier, J., Lüers, J., Mayer, J.-C., Moravek, A., Plake, D., Riederer, M., Rütz, F., Scheibe, M., Siebicke, L., Sörgel, M., Staudt, K., Trebs, I., Tsokankunku, A., Welling, M., Wolff, V., and Zhu, Z:: Coupling processes and exchange of energy and reactive and non-reactive trace gases at a forest site - results of the EGER experiment, Atmos. Chem. Phys., 12, 1923-1950, doi:10.5194/acp-12-1923-2012, 2012.

Frankenberger, E.: Untersuchungen über den Vertikalaustausch in den unteren Dekametern der Atmosphäre, Ann. Meteorol., 4, 358-374, 1951 .

Friehe, C. A. and Khelif, D.: Fast-response aircraft temperature sensors, J. Atmos. Ocean. Tech., 9, 784-795, doi:10.1175/15200426(1992)009<0784:FRATS>2.0.CO;2, 1992.

Gamon, J. A., Cheng, Y., Claudio, H., Mackinney, L., and Sims, D. A.: A mobile tram system for systematic sampling of ecosystem optical properties, Remote Sens. Environ., 103, 246254, doi:10.1016/j.rse.2006.04.006, 2006.

Gerstberger, P., Foken, T., and Kalbitz, K.: The Lehstenbach and Steinkreuz catchments in NE Bavaria, Germany, in: Biogeochemistry of Forested Catchments in a Changing Enivironment, A German Gase Study, Ecological Studies, edited by: Matzner, E., Springer, Heidelberg, 15-41, 2004.

Glickman, T. S.: Glossary of meteorology, Am. Meteorol. Soc., Boston, MA, USA, 2nd Edn., 2000.

Hübner, J., Olesch, J., Falke, H., Meixner, F. X., and Foken, T.: Documentation and Instruction Manual for the Horizontal Mo- bile Measuring System (HMMS), Work Report, University of Bayreuth, Dept. of Micrometeorology, ISSN: 1614-8916, 48, 88, 2011.

Inverarity, G. W.: Correcting airborne temperature data for lags introduced by instruments with two-time-constant responses, J. Atmos. Ocean. Tech., 17, 176-184, doi:10.1175/15200426(2000)017<0176:CATDFL>2.0.CO;2, 2000.

Kaimal, J. C., Wyngaard, J. C., Haugen, D. A., Coté, O. R., Izumi, Y., Caughey, S. J., and Readings, C. J.: Turbulence structure in the convective boundary layer, J. Atmos. Sci., 33, 2152-2169, doi:10.1175/1520 0469(1976)033<2152:TSITCB>2.0.CO;2, 1976.

Klaassen, W., van Breugel, P. B., Moors, E. J., and Nieveen, J. P.: Increased heat fluxes near a forest edge, Theor. Appl. Climatol., 72, 231-243, doi:10.1007/s00704-002-0682-8, 2002.

Langvall, O. and Löfvenius, M. O.: Effect of shelterwood density on nocturnal near-ground temperature, frost injury risk and budburst date of Norway spruce, Forest Ecol. Manag., 168, 149-161, doi:10.1016/S0378-1127(01)00754-X, 2002.

Lee, X. and Black, T. A.: Atmospheric turbulence within and above a douglas-fir stand, Part II: Eddy fluxes of sensible heat and water vapour, Bound.-Lay. Meteorol., 64, 369-389, doi:10.1007/BF00711706, 1993.

Lenschow, D. H.: The Measurement of Air Velocity and Temperature Using the NCAR Buffalo Aircraft Measuring System, NCAR-TN/EDD-74, National Center for Atmospheric Research, Boulder, Colarado, 9, 3 pp., doi:10.5065/D6C8277W, 1972.

Leonard, R. E. and Eschner, A. R.: A treetop tramway system for meteorological studies, Northeastern Forest Experiment Station, Forest Service, US Dept. of Agriculture, US Forest Service Research Paper, NE-92, 10 pp., 1968.

Matlack, G. R. and Litvaitis, J. A.: Forest edges, in: Maintaining Biodiversity in Forest Ecosystems, edited by: Hunter Jr., M. L., Cambridge University Press, Cambridge, UK, 210-233, 1999.

Mayer, J.-C., Hens, K., Rummel, U., Meixner, F. X., and Foken, T.: Moving measurement platforms - specific challenges and corrections, Meteorol. Z., 18, 1-12, doi:10.1127/09412948/2009/0401, 2009.

McCarthy, J.: A method for correcting airborne temperature data for sensor response time, J. Appl. Meteorol., 12, 211-214, doi:10.1175/1520-0450(1973)012<0211:AMFCAT>2.0.CO;2, 1973.

McDonald, D. and David, A. N.: Light environments in temperate New Zealand podocarp rainforests, New Zeal. J. Ecol., 16, 1522, 1992.

Miloshevich, L. M., Paukkunen, A., Vömel, H., and Oltmans, S. J.: Development and Validation of a Time-Lag Correction for Vaisala Radiosonde Humidity Measurements, J. Atmos. Ocean. Tech., 21, 1305-1327, doi:10.1175/15200426(2004)021<1305:DAVOAT>2.0.CO;2, 2004.

Mukammal, E. I.: Some aspects of radiant energy in a pine forest, Theor. Appl. Climatol., 19, 29-52, doi:10.1007/BF02243401, 1971.

Murcia, C.: Edge effects in fragmented forests: implications for conservation, Trends Ecol. Evol., 10, 58-62, doi:10.1016/S01695347(00)88977-6, 1995.

Muschinski, A., Frehlich, R., Jensen, M., Hugo, R., Hoff, A., Eaton, F., and Balsley, B.: Fine-scale measurements of turbulence in the lower troposphere: an intercomparison be- 
tween a kite- and balloon-borne, and a helicopter-borne measurement system, Bound.-Lay. Meteorol., 98, 219-250, doi:10.1023/A:1026520618624, 2001.

Newmark, W. D.: Tanzanian forest edge microclimatic gradients: dynamic patterns, Biotropica, 33, 2-11, doi:10.1646/00063606(2001)033[0002:TFEMGD]2.0.CO;2, 2001.

Ogawa, Y. and Ohara, T.: Observation of the turbulent structure in the planetary boundary layer with a kytoon-mounted ultrasonic anemometer system, Bound.-Lay. Meteorol., 22, 123-131, doi:10.1007/BF00128060, 1982.

Oncley, S. P., Schwenz, K., Burns, S. P., Sun, J., and Monson, R. K.: A cable-borne tram for atmospheric measurements along transects, J. Atmos. Ocean. Tech., 26, 462-473, doi:10.1175/2008JTECHA1158.1, 2009.

Péch, G.: Mobile sampling of solar radiation under conifers, Agr. Forest Meteorol., 37, 15-28, doi:10.1016/0168-1923(86)900250, 1986.

Privette, J. L., Eck, T. F., and Deering, D. W.: Estimating spectral albedo and nadir reflectance through inversion of simple BRDF models with AVHRR/MODIS-like data, J. Geophys. Res.Atmos., 102, 29529-29542, doi:10.1029/97JD01215, 1997.

Örlander, G. and Langvall, O.: The Asa shuttle - a system for mobile sampling of air temperature and radiation, Scand. J. Forest Res., 8, 359-372, doi:10.1080/02827589309382783, 1993.

Rodi, A. R. and Spyers-Duran, P. A.: Analysis of time response of airborne temperature sensors, J. Appl. Meteorol., 11, 554-556, doi:10.1175/1520-0450(1972)011<0554:AOTROA>2.0.CO;2, 1972.

Rodskjer, N. and Kornher, A.: Eine Methode zur Registrierung der räumlichen Verteilung der Globalstrahlung in einem Pflanzenbestand, Theor. Appl. Climatol., 15, 186-190, doi:10.1007/BF02319119, 1967.
Rodskjer, N. and Kornher, A.: Über die Bestimmung der Strahlungsenergie im Wellenlängenbereich von 0.3$0.7 \mu$ in Pflanzenbeständen, Agr. Meteorol., 8, 139-150, doi:10.1016/0002-1571(71)90103-8, 1971.

Saggin, B., Debei, S., and Zaccariotto, M.: Dynamic error correction of a thermometer for atmospheric measurements, Measurement, 30, 223-230, doi:10.1016/S0263-2241(01)00015-X, 2001.

Serafimovich, A., Eder, F., Hübner, J., Falge, E., Voß, L., Sörgel, M., Held, A., Liu, Q., Eigenmann, R., Huber, K., Duarte, H. F., Werle, P., Gast, E., Cieslik, S., Heping, L., and Foken, T.: ExchanGE processes in mountainous Regions (EGER): Documentation of the Intensive Observation Period (IOP3) June, 13th to July, 26th 2011, Work Report, University of Bayreuth, Dept. of Micrometeorology, ISSN: 1614-8916, 47, 137, 2011.

Singh, A., Batalin, M. A., Stealey, M., Chen, V., Hansen, M. H., Harmon, T. C., Sukhatme, G. S., and Kaiser, W. J.: Mobile robot sensing for environmental applications, in: Field and Service Robotics, edited by: Laugier, C. and Siegwart, R., 42, 125-135, Springer, Berlin, Heidelberg, 2008.

Staudt, K. and Foken, T.: Documentation of reference data for the experimental areas of the Bayreuth Center for Ecology and Environmental Research (BayCEER) at the Waldstein site, Work Report, University of Bayreuth, Dept. of Micrometeorology, ISSN: 1614-8916, 35, 35, 2007.

Zahn, A., Weppner, J., Widmann, H., Schlote-Holubek, K., Burger, B., Kühner, T., and Franke, H.: A fast and precise chemiluminescence ozone detector for eddy flux and airborne application, Atmos. Meas. Tech., 5, 363-375, doi:10.5194/amt-5-363-2012, 2012. 